Levin, M. (1934). Paroxysmal hypertonia induced by affect; symptom in man and in lower animals. Archives of Neurology and Psychiatry, 32, 1286.

Lishman, W. A., Symonds, C. P., Whitty, C. W. M., and Willison, R. G. (1962). Seizures induced by movement. Brain, 85, 93.

Patton, V. M. (1967). Ph.D. Thesis. University of Oxford.

Rosenberg, L. E. (1967). Amino Acid Metabolism and Genetic Variation, p. 341 . Ed. by W. L. Nyhan. McGraw-Hill, New York.

Scriver, C. R., Whelan, D. T., Clow, C. L., and Dallaire, L. (1970). Cystinuria: increased prevalence in patients with mental disease. New England fournal of Medicine, 283, 783.

Stevens, H. (1966). Paroxysmal choreo-athetosis. A form of reflex epilepsy. Archives of Neurology, 14, 415.

Visakorpi, J. K., and Hyrske, I. (1960). Urinary amino acids in mentally retarded patients. Annales Paediatriae Fenniae, 6, 112.

Whitty, C. W. M., Lishman, W. A., and FitzGibbon, J., P. (1964). Seizures induced by movement: a form of reflex epilepsy. Lancet, 1, 1403.

N. P. C. Cavanagh, ${ }^{\star}$ J. Bicknell, and F. Howard The Hospital for Sick Children, Great Ormond Street, London; Botleys Park Hospital, Chertsey; and Middlesex Hospital, London.

*Correspondence to Dr. N. P. C. Cavanagh, Department of Neurology, Guy's Hospital, London SE1 9RT.

\section{Treatment of phenothiazine drug intoxication with benztropine}

A Parkinsonian syndrome, dystonia, dyskinesia, and akathisia are well known toxic effects of the phenothiazine drugs, particularly the piperazine derivatives which include perphenazine, fluphenazine, prochlorperazine, and thiopropazate. Dyskinetic states appear early and may be severe, suggesting a diagnosis of tetanus (Ramsden and Froggatt, 1972; Snowdon, 1972). 2 cases of such reactions are reported, 1 presenting with a pseudotetanic state and the other with a generalized epileptiform convulsion.

\section{Case reports}

Case 1. A 10-year-old girl was admitted in October 1972 with a history of having had 2 separate episodes of arching her back, rolling her eyes, and protruding her tongue, accompanied by rigidity of her arms and legs. Each episode lasted only a few minutes and had started about 4 hours previously. On further questioning she had started vomiting 3 days before and had been put on perphenazine $3 \mathrm{mg}$ three times a day by her general practitioner.

On examination she was quite alert and orientated; her neck was extremely stiff but Kernig's sign was negative. Her eyes deviated upwards intermittently but there was no nystagmus, photophobia, or papilloedema. The upper limbs appeared normal, though in the lower limbs the tone was increased and the reflexes very brisk.
Investigations included a lumbar puncture which yielded normal CSF (1 leucocyte and $9 \mathrm{red}$ cells $/ \mathrm{mm}^{3}$ and protein $7 \mathrm{mg} / 100 \mathrm{ml}$ ). White blood count was $5000 / \mathrm{mm}^{3}$ with a normal differential and the ESR was $7 \mathrm{~mm} / \mathrm{hr}$.

After admission she started having almost continuous oculogyric crises associated with opisthotonus and spasms of her facial muscles with difficulty in swallowing. Her clinical state was highly suggestive of tetanus but there was no history of a recent wound and her tetanus toxoid innoculations were up to date.

In view of the recent perphenazine administration she was given benztropine $0.5 \mathrm{mg}$ intravenously. After 1 minute her ocular movements became less severe and in 10 minutes the facial spasm resolved and the swallowing became easier. Half an hour later she was given another $0.5 \mathrm{mg}$ benztropine intravenously and within 5 minutes her back straightened and she was able to flex her neck. Over the next few hours she remained hyperexcitable but had no further spasms and was discharged the following day.

Case 2. In March 1973 a 7-month-old boy was admitted having been given five $3 \mathrm{mg}$ doses of perphenazine syrup. This had been prescribed as a tranquillizer for his mother who had confused it with a similar-looking cough medicine given to the child. Apart from being miserable and sleepy on the day of admission he had no symptoms. On examination he was drowsy and irritable and had increased tone in his upper and lower limbs. There was no neck stiffness. He was admitted for observation.

Six hours later he developed marked rigidity of his limbs accompanied by jerky, dyskinetic movements of his arms and spasms of his facial muscles. The arms were held stiffly up in the air and if pressed down to his sides and then released, immediately returned slowly to their original position. The dystonia and dyskinesia steadily increased in severity until he appeared to be having a grand mal convulsion. Remembering our experience of 6 months before, we gave him benztropine $0.25 \mathrm{mg}$ intravenously; within 1 minute the increased tone diminished, the dyskinetic movements ceased, and a look of relief came over the child's face. There were no further symptoms and he was discharged the next day.

\section{Discussion}

These 2 cases show severe forms of the dyskinetic reactions to a phenothiazine drug. Gupta and Lovejoy (1967) reviewed 20 similar patients under 15 years of age and found the commonest symptoms to be drowsiness, cogwheel rigidity, opisthotonus, and hyper-reflexia, and 2 patients had trismus with convulsions and oculogyric crises. The time of onset was up to 50 hours after the original dose, but in 6 out of 7 cases of accidental ingestion it was within 5 hours. The erroneous diagnosis of tetanus is easily made on the physical signs and referral to an infectious disease unit is not unknown (Mandal and Sengupta, 1972). Diagnoses of encephalitis and, in 
children with malignant disease receiving phenothiazines for nausea, cerebral metastases or irradiation effects may be considered (Cottom and Newman, 1966).

The acute toxic reactions to phenothiazines are self-limiting, the symptoms subsiding in 24 to 48 hours. They can, however, be rapidly and specifically relieved by the anticholinergic/antihistamine group of drugs commonly used for the treatment of Parkinsonism. Such a drug is benztropine methanesulphonate which has been in use since 1952 and is especially effective in relieving 'frozen states' (Doshay, 1956). It has very few side effects, these being mainly due to its mild anticholinergic actions. Given intramuscularly it acts in about 10 minutes and maximally at half an hour, but intravenously it relieves a highly alarming and stressful state almost instantly.

The phenothiazine group of drugs are frequently prescribed to children for their anti-emetic action and the serious nature of the toxic reactions is not widely appreciated. They are commonly seen with overdoses, but may also occur with therapeutic doses. Intoxication is particularly liable to occur in children and is predisposed to by states of fever or dehydration (Duffy, 1971). It is suggested that the phenothiazines should be used with great caution in childhood and avoided if possible. In any case of dyskinesia it is most important to take a full drug history including those prescribed for other members of the household.

\section{Summary}

Two cases of perphenazine-induced dyskinetic toxic state are described. In each the symptoms were rapidly relieved by intravenous benztropine. Toxic extrapyramidal reactions after phenothiazine administration are common in children and the diagnosis should be considered in any case of obscure dyskinesia.

I thank Drs. H. V. L. Finlay and S. M. Tucker for permission to report the cases, and for their advice in writing this paper.

\section{REFERENCES}

Cottom, D. G., and Newman, C. G. H. (1966). Dystonic reactions to phenothiazine derivatives. Archives of Disease in Childhood,

41, 551.
Doshay, L. J. (1956). Five-year study of benztropine (Cogentin) methanesulfonate: outcome in three hundred two cases of paralysis agitans. Fournal of the American Medical Association, 162, 1031.

Duffy, B. (1971). Acute phenothiazine intoxication in children. Medical fournal of Australia, 1, 676.

Gupta, J. M., and Lovejoy, F. H. (1967). Acute phenothiazine toxicity in childhood: a five year survey. Pediatrics, 39, 771 .

Mandal, B. K., and Sengupta, P. (1972). Side effects of phenothiazines. British Medical fournal, 1, 441.
Ramsden, P. D., and Froggatt, D. L. (1972). Idiosyncratic responses to phenothiazines. British Medical fournal, 1, 246. Snowdon, J. (1972). Side effects of phenothiazines. British Medical fournal, 1, 572.

M. H. BELLMAN*

Hillingdon Hospital, Uxbridge, Middlesex.

^Correspondence to M.H.B., Royal Devon and Exeter Hospital, Gladstone Road, Exeter, Devon.

\section{Prolonged obstructive jaundice and haemangiomatosis}

\section{Report of 2 cases}

Haemangiomas are often present at birth, or may appear within the first few months of life. They are for the most part confined to the skin or subcutaneous tissue, but occasionally involve other organs. Few cases require treatment, as spontaneous regression is almost invariable by 6 to 7 years of age (O'Brien, 1964).

Prolonged jaundice of the obstructive type in patients with haemangiomatosis of the skin and placenta have not been previously described, and 2 such patients are presented.

\section{Case reports}

Case 1. A male infant of 3 weeks was admitted on account of prolonged jaundice. There was no family history of jaundice or vascular tumours. Pregnancy and delivery were uncomplicated. The birthweight was $3.35 \mathrm{~kg}$, length $52 \mathrm{~cm}$. A large tumour $(7 \times 5 \times 5 \mathrm{~cm})$ on the placenta at the insertion of the umbilical cord had been noted. Shortly after birth, small red raised spots $2-5 \mathrm{~mm}$ diameter on the patient's face were noted, and within the next few days several similar lesions of the 'strawberry naevus' type appeared on other parts of the body. Sepsis was suspected, and a course of ampicillin and kanamycin was given.

On admission the infant was severely jaundiced, but his overall condition was good. Physical examination revealed haemangiomas (diameter 1-4 $\mathrm{mm}$ ) on the skin, buccal mucosa, anal mucosa, and iris (Fig.). Moderate hepatosplenomegaly was present.

While in hospital his stools were described as being light yellow, but never clay-coloured. Bile was present in the urine. Weight gain was normal. Jaundice of the obstructive type was suspected and exploratory laparotomy was considered. Liver function tests were inconclusive, with normal alkaline phosphatases, raised SGPT (Table), and a high fraction $(\sim 70 \%)$ of conjugated bilirubin. Thrombocyte count and coagulation status (fibrinogen, prothrombin, thromboplastin time, kaolincephalin time, and fibrinolysis) were normal. A liver scintigraph was normal. From the age of 5 weeks the haemangiomas started to diminish, and simultaneously the serum bilirubin level began to fall. 